International Journal of Social Sciences and Humanities
Available online at http://sciencescholar.us/journal/index.php/ijssh
Vol. 3 No. 2, August 2019, pages: $1 \sim 9$
e-ISSN: 2550-7001, p-ISSN: 2550-701X
https://doi.org/10.29332/ijssh.v3n2.283

\title{
Renewable Sources and Natural Disasters: A Look From Legal Order in Professional Training
}

\author{
CrossMark \\ Antonio Vázquez Pérez a, María Rodríguez Gámez ${ }^{\mathrm{b}}$, Carlos Gustavo Villacreses Viteri ${ }^{\mathrm{c}}$, \\ Miguel Castro Fernández ${ }^{\mathrm{d}}$
}

Article history: Received 27 December 2018, Accepted: 30 April 2019, Published: 9 May 2019

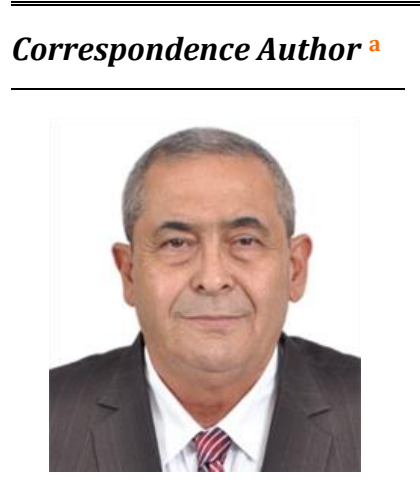

Keywords

crises;

environmental;

pollution;

renewable energy;

technologies;

\begin{abstract}
The crises linked to the high costs of oil and environmental pollution have led to think about the large-scale use of systems that use renewable energy sources, as a measure to mitigate these impacts. In Cuba there are more than 10,000 installations that take advantage of renewable sources using different technologies, these are of small format; but also there are conditions of a renewable potential distributed throughout the national territory, which allows us to continue introducing these practices in a larger scale and format. The work deals, with the possibilities offered by the use of the potential of the renewable energy source as a measure of economic savings and reduction of disaster risks, exposing the need to link the facilities that take advantage of these resources, with the stability of the energy services for the confrontation of natural disasters and for exceptional situations, in addition to the rescue of certain energetic cultural traditions, which can help in the formation of social habits of efficiency and austerity in consumption, propitiating the reduction of the associated environmental impacts and the promulgation of a legal norm that protects and orders the penetration of renewable sources in the national energy matrix.
\end{abstract}

e-ISSN: 2550-7001, p-ISSN: 2550-701X ๑ Copyright 2019. The Author. SS Journals Published by Universidad Técnica de Manabí. This is an open-access article under the CC BY-SA 4.0 license (https://creativecommons.org/licenses/by-sa/4.0/) All rights reserved.

a Universidad Técnica de Manabí, Portoviejo, Ecuador

b Universidad Técnica de Manabí, Portoviejo, Ecuador

c Universidad Técnica de Manabí, Portoviejo, Ecuador

d Universidad Politécnica de La Habana. Cujae, Cuba 


\section{Contents}

Abstract

1. Introduction

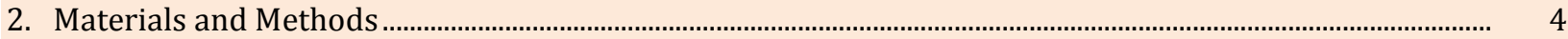

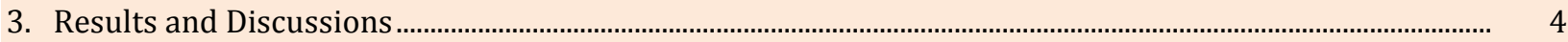

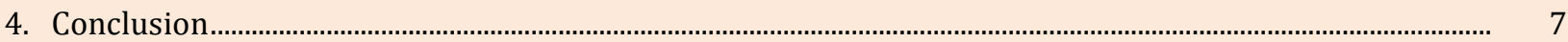

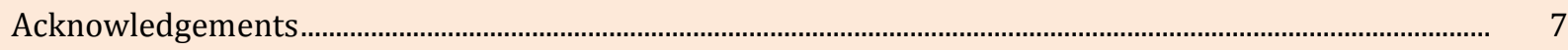

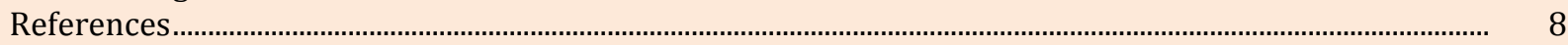

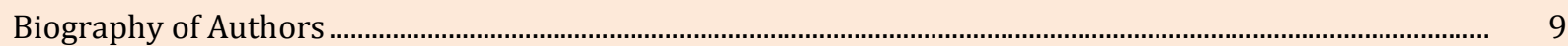

\section{Introduction}

It is currently difficult to distinguish any social activity, where none of the modern ways and ways of using energy has linked. You can see a wide range of technological devices that require for their operation, the consumption of electricity or a primary source of energy. For almost four hundred millennia and until the dawn of the eighteenth century, the technological and art development has was based on the use of the FRE; but the industrial revolution meant a strong increase in the demand for raw materials and energy (Vázquez, 2012).

The spectacular leap in technological development occurred, when, the end of the 19th century, petroleum and nuclear fuels appeared as elements that would facilitate the eternal solution to the problems of development in terms of their energy needs, the design of the prevailing political and economic system, based on an uncontrolled race for consumption, they made these sources be considered as unlimited and infinite, without presuming the physical exhaustion of the reserves of these resources and the environmental impact associated with the intensive exploitation of hydrocarbons and nuclear fuels.

The sublime and positive has seen the light next to the negative and despicable of this erroneous doctrine of development, being responsible for leading the human species to live in two worlds: one endowed with all the possible comforts and another that faces each day to a desperate struggle for survival and against hunger, illiteracy, and disease; a first world that has achieved this condition based on the sustained depauperation of a third polluted world, desertified and impoverished in its natural resources (Colectivo de autores, 2007).

The conditions of the world capitalist economy until the 70s led to overconsumption and waste of fossil fuels, but this policy would finally bring about the appearance of the first oil crisis. The price of the kWh generated that until now did not involve significant costs began to rise, a situation that continues to this day. In 1984 a group of German scientists detected signs of deterioration in the forests, in that same year, it was reported that the land lost annually eleven million hectares of forests and in 1985 two British scientists reported the finding of a hole in the ozone layer over the Antarctic (Colectivo de autores, 2007).

The irresponsible act of man to achieve an irrational quality of life does not skimp on continuing to waste natural resources that are depleted at an unsustainable pace, leaving behind more pollution and negative impacts. Despite the advances experienced at the price of irresponsibly undermining the stability of life on the planet, the high number of people without access to electricity, around 1300 million, is still unacceptable, representing about $20 \%$ of the population. World population (IAEA, 2011). But today the situation is diametrically different; with very high prices of fossil fuels, especially oil, promoter of the well-known energy dependence, with the penetration of sophisticated and expensive technologies.

In this reflux of contradictions and impacts, a general interest for environmental protection has gradually established, as well as the preservation of the precepts of energy, technological and economic independence of the states. In this scenario, the FREs has a practical capacity to act as an adequate solution alternative for the achievement of the proposed objectives, in order to safeguard the health of the planet and achieve the goals of sustainable development (Cedeno et al., 2017).

The imprint of distributed and existentially democratic renewable sources, which cannot be blocked or used as an instrument of power, are initially called to put a brake on the race for environmental impacts caused by traditional technologies and then turn into a energetic preferential source, creating a new archetype of energy, economic, technological and political independence. For this, it will be necessary to 
transform the current centralized and devouring fossil energy base, by a decentralized matrix based on the efficient use of renewable resources, from generation to consumption (Gamez et al., 2017).

The technical characteristics of the centralized electrical system presents considerable vulnerabilities in relation to the impacts of natural disasters. In Cuba, there is evidence of damage caused by extreme hydrometeorological phenomena (hurricanes) and the impact of a high-intensity earthquake. Both phenomena are the main threats of natural disasters in the Cuban territory (Antonio \& María, 2010).

The unsustainability of the contemporary energy system is a reality made explicit in several scientific results, both nationally and internationally. The use of the energy contained in the concentrated carriers and the centralized design of the energy management, constituted at the time the key elements that distinguished, but the situation is different, where the depletion of fossil resources is marking an accelerated unstoppable rhythm in the rise of the price of energy and where the centralization of the supply isn't able to overcome the losses that gravitate in the efficiency of these systems.

The current world society is committed to the implementation of a new energy policy, which is capable of adopting a new paradigm of sustainability in the different planes of life, resulting in a goal that can not be achieved through the operation of the current energy scheme, which It means undertaking the search for innovative technical solutions, which enable the efficient use of renewable energy sources in a distributed design of generation, supply, and consumption.

In Cuba, the Cuban Electricity Law has was published in 1975 (Council of Ministers, 1975). This legal document protects the social relations that derive from the management of the centralized electrical system in the country and in none of its parts are social relations derived from the use of renewable energy sources, there being no published Law so far specifically regulate these relationships. The problematic situation from which the research starts has linked, with the lack of an explicitly argued theoretical formulation, about the importance of the FRE in the confrontation to the situations of natural disasters and the need to promulgate a Cuban juridical norm, that of treatment to the social relations that derive from the use of these resources.

The hypothesis is based on the fact that the results of the research can serve, to deepen the importance of renewable sources for the confrontation of natural disasters, as well as to expose the theoretical content of the studies and evaluations that are carried out to formulate the new Energy Law in Cuba, where differentiation can be made in terms of the treatment of social relationships derived from the use of the FRE and that can serve to help in the formation of an energetic legal culture during undergraduate and postgraduate training in higher education (Chilán et al., 2018).

The general objective focuses on providing the essential arguments that should characterize the Cuban legal policy, in terms of regulating the relationships derived from the RES, as well as demonstrating the potential of the country for the development of these sources. The specific objectives have been focused on explicitly exposing the possibilities of the potential of renewable sources in the country, to achieve the diversification of the energy matrix, exposing the advantages associated with their use to deal with situations of natural disasters and highlight the role of these for achieving the goals of sustainable development.

The methodology used is based on the general method of the materialist dialectic offered by the MarxistLeninist philosophy, as the basis and foundation of the other general methods of the sciences, which has allowed to analyze the evolution of the energy profile and the associated regulatory framework, taking into account the concrete historical moment in which it was developed, as well as to determine the utility of the FRE for the confrontation to the situations of natural disasters.

Also important is the use of the analysis-synthesis method in the study of available bibliographic material. The historical-logical for the offering of precise considerations relative to the logic of the social development of the corresponding topic, since its evolution in previous years. The method of induction and deduction, to define the existence of the content of the object of study, to obtain conclusions, allowing thereby inferring the essences, causes and why of the conclusion.

The legal theoretical method for the examination of the various classical and modern theories that prevail in the doctrine regarding legal values, and those that acquire the appellation of "superiors". Likewise, the comparative legal method, to evaluate the regulation of these relationships in other legal systems and, finally, in the analysis of the legal norm that interests research and the social relations that it generates.

The research was based on the exegetical method, which allows the philosophical and historical interpretation related to the evolution of the legal system linked to the energetic profile, on an international and country scale. The investigative techniques of document revision, texts, and legislation have used to

Pérez, A. V., Gámez, M. R., Viteri, C. G. V., \& Fernández, M. C. (2019). Renewable sources and natural disasters: A look from legal order in professional training. International Journal of Social Sciences and Humanities, 3(2), 1-9. https://doi.org/10.29332/ijssh.v3n2.283 
obtain the adequate and truthful information that implies the arrival of accurate considerations on the subject. All the above applies to the effects of unveiling the essence of the scientific problem, in the processing of information and the definition of the system of central and operational categories. In addition to reaching the corresponding conclusions, which may be useful for the State Legislative Body, as well as to enrich the issues of energy legal culture for the training of students in undergraduate and graduate courses in higher education.

\section{Materials and Methods}

The results of the research can serve to deepen the importance of renewable sources for the confrontation of natural disasters, as well as to expose the theoretical content of the studies and evaluations that are carried out to formulate the new Energy Law in Cuba, where differentiation can be made in terms of the treatment of social relationships derived from the use of the FRE and that can serve to help in the formation of an energetic legal culture during undergraduate and postgraduate training in higher education

The general objective focuses on providing the essential arguments that should characterize the Cuban legal policy, in terms of regulating the relationships derived from the renewable energy source, as well as demonstrating the potential of the country for the development of these sources.

The specific objectives have focused on explicitly exposing the possibilities of the potential of renewable sources in the country, to achieve the diversification of the energy matrix, exposing the advantages associated with their use to deal with situations of natural disasters and highlight the role of these for achieving the goals of sustainable development. The methodology used is based on the general method of the materialist dialectic offered by the Marxist-Leninist philosophy, as the basis and foundation of the other general methods of the sciences, which has allowed to analyze the evolution of the energy profile and the associated regulatory framework, taking into account the concrete historical moment in which it was developed, as well as to determine the utility of the FRE for the confrontation to the situations of natural disasters. Also important is the use of the analysis-synthesis method in the study of available bibliographic material. The historical-logical for the offering of precise considerations relative to the logic of the social development of the corresponding topic, since its evolution in previous years.

The method of induction and deduction, to define the existence of the content of the object of study, to obtain conclusions, allowing thereby inferring the essences, causes and why of the conclusion. The legal theoretical method for the examination of the various classical and modern theories that prevail in the doctrine regarding legal values, and those that acquire the appellation of "superiors". Likewise, the comparative legal method, to evaluate the regulation of these relationships in other legal systems and, finally, in the analysis of the legal norm that interests research and the social relations that it generates.

The research was based on the exegetical method, which allows the philosophical and historical interpretation related to the evolution of the legal system linked to the energetic profile, on an international and country scale. The investigative techniques of document revision, texts, and legislation have used to obtain the adequate and truthful information that implies the arrival of accurate considerations on the subject.

All the above applies to the effects of unveiling the essence of the scientific problem, in the processing of information and the definition of the system of central and operational categories. In addition to reaching the corresponding conclusions, which may be useful for the State Legislative Body, as well as to enrich the issues of energy legal culture for the training of students in undergraduate and graduate courses in higher education.

\section{Results and Discussions}

The kWh generated during the first half of the twentieth century was very cheap, with very low oil prices and the low maturity of the sciences of that time, did not allow to appreciate the deep damage that the exploitation of fossil fuels was infringing the natural environment of the planet, to this situation was incorporated the technological dependence derived from the unequal technical-scientific development of the nations.

Currently, it is not conceived to reach the challenge of sustainable development, based on the exploitation of fossil fuels. The energy losses associated with the distribution and transportation of electricity in the 
electricity grid imply that in order to guarantee the final consumption of one $\mathrm{kWh}$, almost twice as much must be generated, adding that during this process, more than $30 \%$ of the primary energy contained in the oil, the rest being wasted in a kind of progressive poisoning of life on earth.

The FRE guarantee the generation of energy services, with zero virtual cost for fuel concepts; a drastic reduction of environmental impacts and in most cases it is possible to achieve technological sustainability.

In the potential of the FRE, the energy reserves necessary to sustain the current and prospective development of Cuban society lie. The advantages of using these renewable resources lie in their use based on the scheme of a distributed generation.

\section{The potentiality of the renewable energy source in Cuba}

In the use of bioenergy, the immediate perspectives are located in the growth of the role of renewable resources in the national energy matrix, currently, there are around 60 sugar industries operating throughout the length and breadth of the region. Territory. Sugar cane is a C4 vegetable, the most efficient known to capture solar energy, considering an average rate of $300 \mathrm{kWh} /$ tonm2, with zero virtual fuel cost (Torres, 2012).

Introducing technological modifications in the boilers of these industries, so that they can reach between 80-90 MPa minimum; being able to take advantage of the ground bagasse plus $50 \%$ of the residues of the crops left in the field; generating electricity for 290 days a year; in a harvest where three million tons of sugar are produced, it would be possible to generate around 9,000 GWh per year (Torres, 2012), which represent approximately $45 \%$ of the total generation of the country (National Cargo Office, 2010).

Another of the variants of biomass use is related to the gasification of agroforestry residuals, through the installation of small and medium bioelectric power plants.

In the national territory, there is 813,176 ha infected with marabou, being the province of Camagüey the most affected with $33 \%$ of these. Forests occupy an area equivalent to 2.06 .082 ha, which represents $19.15 \%$ of the total territory of the country, with the possibility of using the residuals of controlled pruning and felling, through the repopulation of energetic forests.

The alcohol industry would be another valuable result of the program for the efficient use of sugarcane biomass and crop recovery.

Another important option for the use of biomass is the use of biogas from agro-industrial waste and urban solid waste, for use as fuel in the cooking of specific targets and the generation of electricity.

The behavior of the Cuban solar potential has studied in 10,920,280 ha, being able to verify that the values oscillate between $5,164 \mathrm{kWh} / \mathrm{m} 2$ in the center-east part of the Isle of Youth, up to $6,200 \mathrm{kWh} / \mathrm{m}^{2}$ in the part center of the province Santiago de Cuba. The country average is equivalent to $5,786 \mathrm{kWh} / \mathrm{m}^{2}$.

It has been possible to calculate that with these values of solar radiation, they can be generated during the life cycle of the technology for each installed $\mathrm{kW}$, between $37 \mathrm{MWh}$ in the areas of lower radiation, up to 44.5 MWh in the highest radiation sites, representing a fuel saving between 3,182 tons and 3,827 tons, stopping the emission of 9.83 tons of $\mathrm{CO}_{2}$ into the atmosphere and 11.83 tons of $\mathrm{CO} 2$.

The geographical conditions of Cuba and the characteristics of its water structure, imply that the hydraulic potential is integrated mostly by small and medium power sources; the analysis of the data allows to determine that at present, there are 233 sources studied in the country that generate hydroelectric energy, these are located in dams and dams. The analysis of this information has allowed us to calculate that they have an estimated flow of 1,648 m3/ s and affect a territorial space equivalent to 11,750.1 km2 (Rodríguez, 2011).

In the national territory, there is no mention of large areas with good wind density; but there are somewhere acceptable values with economic attractiveness have exhibited, fundamentally when wind farms connected to the electricity grid has implanted, in order to provide the system with energy availability. Other applications have related to the use in pumping water, this is one of the oldest modalities in the world and in Cuba.

Sites such as Cayo Coco, Cayo Sabinal, Punta de Maisí, Cayo Guillermo, Cayo Santa María, the Island of Turiguanó and some enclaves, present great possibilities of interconnection to the electric grid in blocks of about $30 \mathrm{MW}$. The results obtained with the prospection and evaluation of the Cuban wind potential that had carried out since 1991; characterize the possibilities studied up to now. The sites analyzed with measurements of more than 2 years have allowed preparing investment projects for the use of this energy.

Pérez, A. V., Gámez, M. R., Viteri, C. G. V., \& Fernández, M. C. (2019). Renewable sources and natural disasters: A look from legal order in professional training. International Journal of Social Sciences and Humanities, 3(2), 1-9. https://doi.org/10.29332/ijssh.v3n2.283 
In summary, it can be affirmed that in Cuba there are real possibilities for undertaking the sustainable diversification of the energy matrix, based on the use of the existing potentials of the renewable energy source.

\section{Evolution of energetic legal normativism}

Throughout history, human claims to legally regulate the use of FRE have been diverse. Long before the electric invention was developed as a lucrative business, the first regulative attempt of which one has knowledge and dates of ancient Greece takes place; Socrates said that the ideal house should be cool in summer and warm in winter, explaining that "in houses facing south, the sun penetrates the portico in winter, while in summer the solar arc described rises above our heads and by over the roof, so there is shade "(José, 2004).

A more specific and acute regulatory claim is found in Rome, contained in the Justinian Code on the guarantee of sun rights, being incorporated into Roman law and noted that: "if an object is placed in a way to hide the sun from a heliocaminus, it must be affirmed that such an object creates shadow in a place where sunlight is an absolute necessity, this is in violation of the right of heliocaminus to the sun "(José, 2004).

The trends for the legal normativism of the systems that take advantage of the FRE, has aroused a special interest in recent years, regionally European countries lead the initiative with the enactment and enforcement of a set of rules, which as a regulatory framework they favor and protect the introduction of these systems, in the pretension to diversify their energy matrix.

In July 2004, the Renewable Energy Law was enacted in Germany; but really in its content, it only deals with the energy of the wind (Federal Ministry of Germany for the Environment, 2004). Similarly, the Spanish Law reveals a marked interest in incentives and economic advantages that favor the introduction of renewable systems. In Argentina, where Law 25019/1998 was promulgated; Decree No. 1597/1999, National Regime for Solar Photovoltaic and Wind Energy and Law 26190/2006, National Promotion Regime for the use of FRE for the production of electricity; Provincial laws and regulations were also enacted (González J. and Marcelo Mula, 2008).

In Uruguay, two Decrees were published, No. 267/2005 and No. 389/2005, as well as the Executive Power, established Decrees No. 77/006 and No. 397/007. In the Dominican Republic, Law No. 57-07, of Incentive for Renewable Energies and Special Regimes, was approved on May 7, 2007, and its respective regulations promulgated on June 11, 2008 (González \& Mula, 2008).

In Ecuador, where around $60 \%$ of the electricity consumed comes from renewable sources, there is even a Ministry of Renewable Energies, highlighting the importance that the government of this country grants to the use of these resources, where the Law No. 86 for the promotion of non-conventional energies. However, all the efforts made in Cuba to introduce the use of renewable sources and the political will expressed in the Guidelines for Economic and Social Policy of the Party and the Revolution (CC PCC, CUBA 2011) and implemented by the state, still no specific legal norm has been promulgated, which protects the penetration of the FREs in the national energy matrix.

In a scenario characterized by more than 100 years of development, planning and consolidation of a monoenergetic, electrical system par excellence, centralized, which depends for its operation on oil, which has been sufficiently protected by the promulgation of regulations and regulations that have consolidated the social relations that derive from it, it is required to deploy a resolute regulatory will in the legal order, which protects and promotes the ordering of the FRE and its penetration in the national energy matrix.

A law that can raise the principles of sustainable development, the search for innovative alternatives in the solution of development problems. The rescue of energetic traditions diluted in time and modernity, linking the possibilities and capabilities of the localities of the country, in guarantee an energy base at the expense of their own resources, where efficiency and quality occupy the focal point of society's attention.

\section{Importance of the FRE in the reduction of disasters}

Of the risks of natural disasters that more incidences present in the Cuban energy infrastructure, are the extreme hydro-meteorological phenomena and the earthquakes. The most vulnerable elements of the SEN lie in the system of transportation and distribution of energy, which can cause cuts, interruptions and even the 
collapse of the system, requiring the investment of large resources for its restoration, leaving behind affectations that may last several days or weeks, with considerable economic losses.

The distributed and, in some cases, punctual nature of renewable systems, their limited size, and their low technical complexity guarantee the vitality of energy services in the conditions that the centralized system has collapsed. The application of protection measures, their removal, and replacement can be carried out in a short time and with the economy of forces and means, being in better conditions than the conventional system, to guarantee the vitality of energy services.

\section{Conclusion}

The information related to the existence of renewable potential is presented, which corroborates the possibilities of the country to undertake the diversification of the national energy matrix, with a base of sustainable development, which guarantees to create the bases and strengthen the energy and technological independence; the study of the legislative experiences assumed by other countries, as well as the need to undertake the widespread use of the FRE and its penetration in the Cuban energy base, demonstrate the need to enact a Law that explicitly protects and orders the use of these resources to ensure energy services on a sustainable basis. The results of the research can be used in order to enrich the bibliography related to the energetic legal culture, in the undergraduate and postgraduate education of higher education.

\section{Acknowledgments}

The authors thank Ph.D. Julio Torres for the valuable information provided for the development of the research.

Pérez, A. V., Gámez, M. R., Viteri, C. G. V., \& Fernández, M. C. (2019). Renewable sources and natural disasters: A look from legal order in professional training. International Journal of Social Sciences and Humanities, 3(2), 1-9. https://doi.org/10.29332/ijssh.v3n2.283 


\section{References}

Antonio, V., \& María R. (2010). Capacity of the DG mode, in the interest of guaranteeing the electric service to the vital sectors of society in disaster situations, applying a manager of database. CD. Scientific Convention on Engineering and Architecture, ISBN: 978-959-31-1.

Cedeno, M. L. D., Arteaga, M. G. D., Perez, A. V., \& Arteaga, M. L. D. (2017). Regulatory framework for renewable energy sources in Ecuador case study province of Manabi. International Journal of Social Sciences and Humanities, 1(2), 29-42. https://doi.org/10.29332/ijssh.v1n2.33

Chilán, J. C. H., Torres, S. G. P., Machuca, B. I. F., Cordova, A. J. T., Pérez, C. A. M., \& Gamez, M. R. (2018). Social impact of renewable energy sources in the province of Loja. International Journal of Physical Sciences and Engineering, 2(1), 13-25. https://doi.org/10.29332/ijpse.v2n1.79

Collective authors, (2007). Cuban Environmental Law. Editorial Félix Varela. Second edition updated and enlarged. ISBN 978-959-07-0434-5.

Council of Ministers. (1975). Cuba, Electric Law No. 1287. Official Gazette of the Republic of Cuba, Ordinary edition: p. 3.

de Cuba, G. (2011). Sixth Congress of the Communist Party of Cuba. Resolution on the guidelines of the economic and social policy of the Party and the Revolution.

Federal Ministry of Environment Germany. (2004). Extract from Act Revising the Legislation on Renewable Energy Sources in the Electricity Sector1. only Wind Energy), 68 pages. DEWI Magazin Nr. 25. (BMU.): 1.

Gamez, M. R., Perez, A. V., Sera, A. S., \& Ronquillo, Z. M. (2017). Renewable energy sources and local development. International Journal of Social Sciences and Humanities, 1(2), 10-19. https://doi.org/10.29332/ijssh.v1n2.31

González, J. \& Marcelo, M. (2008). New technologies based on renewable energies, barriers to their insertion and promotion policies. Wind situation in some Latin American countries. Book prepared from the "Seminar of Trainers in Training of Renewable Energies", Guatemala.

IAEA (2011). World Energy Outlook, Executive Summary. OECD, IEA www.iea.org

National Cargo Office (2010). Work report. UNE

Rodríguez G.M. (2012). The organization and planning of the FREs in the Island of Cuba from a territorial perspective Case study in the municipality of Guama from a Geoportal. Collection of CIEMAT documents. NIP0 721-12-044-4. ISBN: 978-84-7834-689-9.

Santamarta, J. (2004). Renewable energies are the future. World Watch, 22 (3440.16).

Torres, J. (2012). Technical Report: "Proposal of a medium-long-term National Program for the generation of electricity in Cuba from sugarcane biomass." Work report Vice President of Development and Projects of CUBASOLAR.

Vázquez A. (2012). The Systems that take advantage of the FRE, from a legal perspective." Faculty of Law of the Universidad de Oriente. Degree Thesis. 


\section{Biography of Authors}

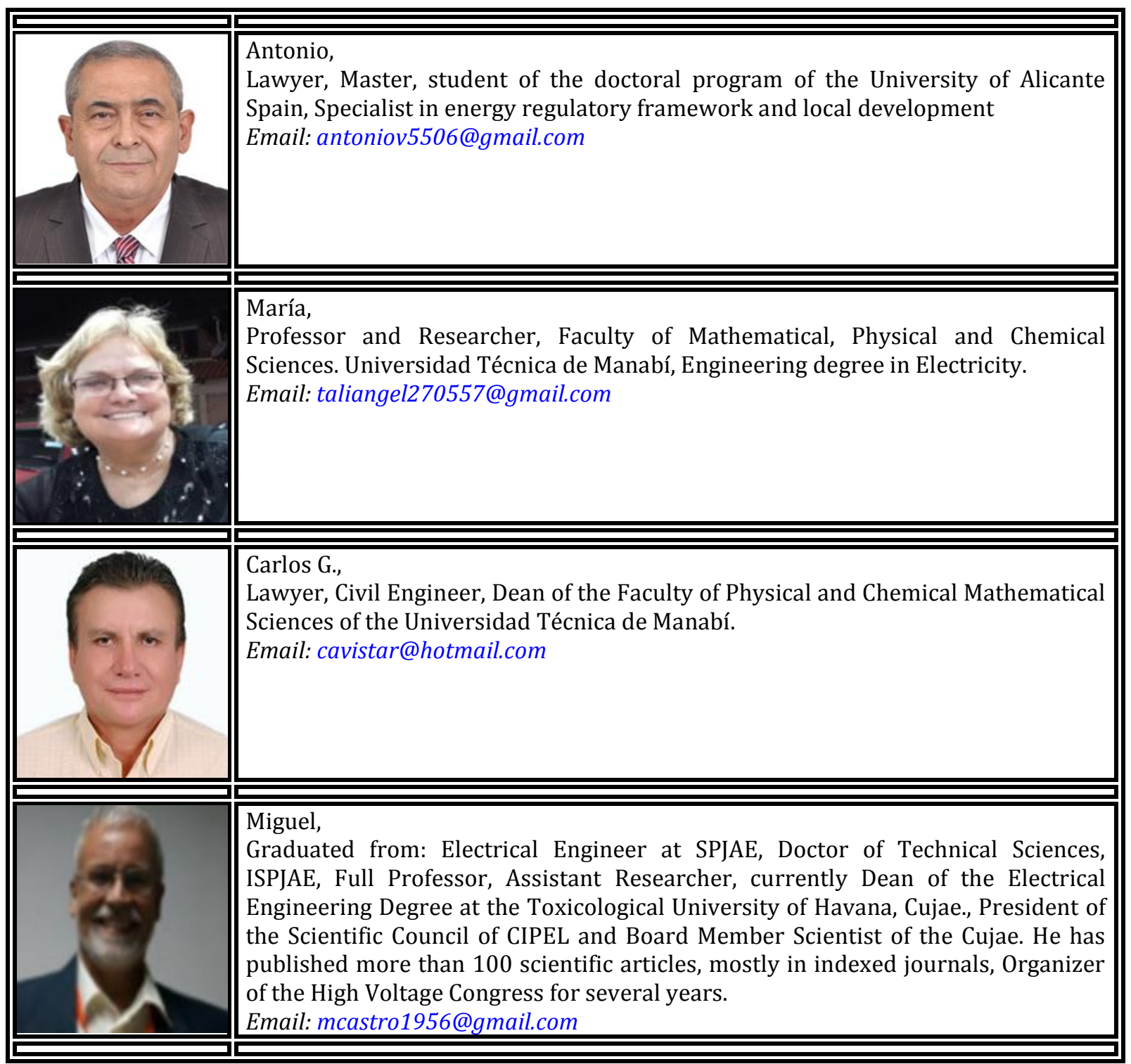

Pérez, A. V., Gámez, M. R., Viteri, C. G. V., \& Fernández, M. C. (2019). Renewable sources and natural disasters: A look from legal order in professional training. International Journal of Social Sciences and Humanities, 3(2), 1-9. https://doi.org/10.29332/ijssh.v3n2.283 